\title{
Formulation and evaluation of effervescent tablets: a review
}

\author{
Patel Salim G'*, Siddaiah $\mathbf{M}^{2}$ \\ ${ }^{1}$ Department of Pharmacy, Bhagwant University, Sikar Road, Ajmer, Rajasthan. India \\ ${ }^{2}$ Jawaharlal Nehru Technological University ' Anantpuram, A.P., India
}

\begin{abstract}
Oral dosage forms are the most popular way of taking medication, despite having some disadvantages compared with other methods like risk of slow absorption of the medicament, which can be overcome by administering the drug in liquid form, there fore, possibly allowing the use of a lower dosage. However, instability of many drugs in liquid dosage form limits its use. Effervescent technique can be used as alternate to develop a dosage form which can accelerate drug disintegration and dissolution, is usually applied in quick release preparations. Along with the development of new pharmaceutical technique, effervescent tablet are more and more extensively to adjust the behaviour of drug release, such as in sustained and controlled release preparations, pulsatile drug delivery systems, and so on. This review demonstrated the new applying of effervescent technique in effervescent tablets.
\end{abstract}

Keywords: Effervescent Tablet, Sustained release, Floating Delivery System

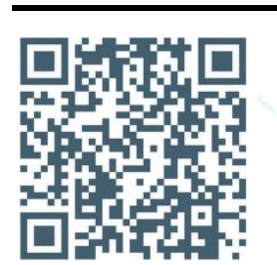

Article Info: Received 28 Sep, 2018; Review Completed 27 Oct 2018; Accepted 29 Oct 2018; Available online 15 Nov 2018

Cite this article as:

Patel SG, Siddaiah M, Formulation and evaluation of effervescent tablets: a review, Journal of Drug Delivery and

Therapeutics. 2018; 8(6): 296-303 DOI: http://dx.doi.org/10.22270/jddt.v8i6.2021

*Address for Correspondence:

Patel Salim G, Department of Pharmacy, Bhagwant University, Sikar Road, Ajmer, Rajasthan. India

\section{INTRODUCTION}

Oral drug delivery has been known for decades as the most widely utilized route of administered among all the routes that have been employed for the systemic delivery of drug via various pharmaceutical products of different dosage forms. The reasons that the oral route achieved such popularity may be in part attributed to its ease of administration.1-2 Oral sustained drug delivery system is complicated by limited gastric residence times (GRTs). Rapid GI transit can prevent complete drug release in the absorption zone and reduce the efficacy of the administered dose. ${ }^{3-4}$

Effervescent tablets are becoming increasingly popular in a variety of sectors including supplements and pharmaceutical use due to the ease in which they can be consumed. Effervescent tablets are designed to break in contact with liquid such as water or juice, often causing the tablet to dissolve into a solution. 5

These buoyant delivery systems utilize matrices prepared with swellable polymers such as Methocel or poly saccharides, e.g., chitosan, and effervescent components, e.g., sodium bicarbonate and citric or tartaric acid 6 or matrices containing chambers of liquid that gasify at body temperature ${ }^{7-8}$. Flotation of a drug delivery system in the stomach can be achieved by incorporating a floating chamber filled with vacuum, air or an inert gas ${ }^{9}$.Gas can be introduced into the floating chamber by the volatilization of an organic solvent (e.g. Ether or cyclopentane) or by the $\mathrm{CO}_{2}$ produced as a result of an effervescent reaction between organic acids and carbonate-bicarbonate salts ${ }^{10}$. The matrices are fabricated so that upon arrival in the stomach, carbon dioxide is liberated by the acidity of the gastric contents and is entrapped in the jellified hydrocolloid. This produces an upward motion of the dosage form and maintains its buoyancy. A decrease in specific gravity causes the dosage form to float on the chyme $^{11-12}$. Recently a multiple-unit type of floating pill, which generates carbon dioxide gas, has been developed. The system consisted of sustained- release pills as seeds surrounded by double layers. The inner layer was an effervescent layer containing both sodium bicarbonate and tartaric acid. The outer layer was a swellable membrane layer containing mainly polyvinyl acetate and purified shellac. Moreover, the effervescent layer was divided into two sub layers to avoid direct contact between sodium bicarbonate and tartaric acid. Sodium bicarbonate was contained in the inner sublayer and tartaric acid was in the outer layer. When the system was immersed in a buffer solution at $37^{\circ} \mathrm{C}$, it sank at once in the solution and formed swollen pills, like balloons, with a density much lower than $1 \mathrm{~g} / \mathrm{ml}$. The reaction was due to carbon dioxide generated 
by neutralization in the inner effervescent layers with the diffusion of water through the outer swellable membrane layers. The system was found to float completely within 10 min and approximately 80\%remained floating over a period of $5 \mathrm{hr}$ irrespective of $\mathrm{pH}$ and viscosity of the test medium. While the system was floating, a drug ( $p$-amino benzoic acid) was released. A variant of this approach utilizing citric acid (anhydrous) and sodium bicarbonate as effervescing agents and $\mathrm{HPC}-\mathrm{H}$ grade as a release controlling agent has also been reported. In vitro results indicated a linear decrease in the FT of the tablets with an increase in the amount of effervescing agents in the range of $10-20 \%$. Attempts have also been made to develop SR floating tablets using a mixture of sodium bicarbonate, citric acid and chitosan. ${ }^{13}$

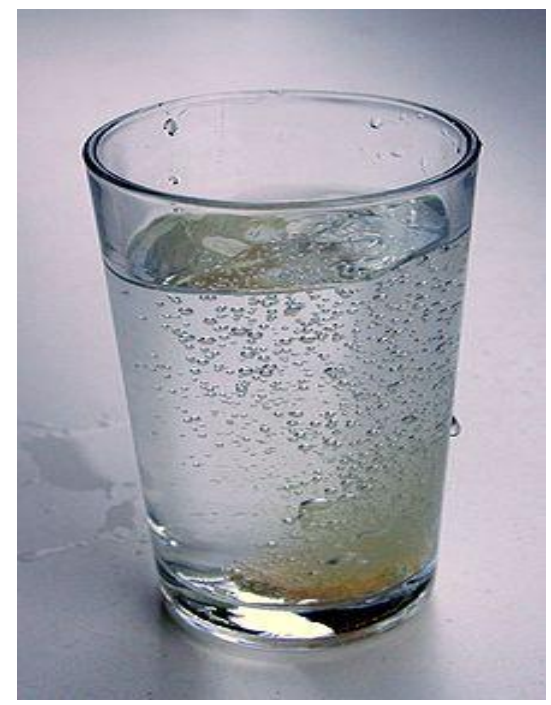

Figure 1: An effervescent tablet in a glass of water

Effervescent or carbon tablets are tablets which are designed to dissolve in water, and release carbon dioxide. ${ }^{14-16}$ They are products of compression of component ingredients in the form of powders into a dense mass, which is packaged in blister pack, or with a hermetically sealed package with incorporated desiccant in the cap. To use them, they are dropped into water to make a solution. The powdered ingredients are also packaged and sold as effervescent powders or may be granulated and sold as effervescent granules. Generally powdered ingredients are first granulized before being made into tablets ${ }^{17-18}$

Effervescent tablets are becoming increasingly popular in a variety of sectors including supplements and pharmaceutical use due to the ease in which they can be consumed.

Effervescent tablets are designed to break in contact with liquid such as water or juice, often causing the tablet to dissolve into a solution. This makes effervescent tablets the preferred choice of many, including people who are taking tablets medicinally as well as a dietary supplement. ${ }^{19}$

\section{Here we look at 5 benefits of effervescent tablets over regular tablets. ${ }^{20}$}

\section{Pleasant Taste Compared to Regular Tablets}

Effervescent tablets are so popular due to the fact they can be dissolved in a liquid such as water or fruit juice, meaning that they often taste better than regular tablets. Conventional tablets dissolve slowly which can result in reduced absorption rates, effervescent tablets, in contrast, dissolve quickly and completely, meaning you get the full benefit from the ingredients.

\section{Distributed More Evenly}

Conventional tablets dissolve gradually in the stomach once ingested and can sometimes only partially dissolve which can lead to irritation in some cases. The benefit of effervescent tablets is that they dissolve completely and evenly meaning that localised concentrations of the ingredients cannot occur. This means not only a better taste but also less chance of irritation and a more efficient means of ingesting the ingredients.

\section{Increased Liquid Intake}

Effervescent tablets provide the nutritional benefits intended, but in addition to this they also increase liquid intake. This can be especially beneficial if you are dehydrated or ill and not ingesting as much fluid as usual. Effervescent tablets can be a fantastic way of rehydrating as well as reaping the benefits you are taking the tablets for whether this is a dietary supplement, herbally or medicinally.

\section{Easy Alternative to Regular Tablets}

They can be a great alternative for those who may have trouble swallowing either due to illness or age. Older individuals may have difficulty swallowing but need to take medication or supplements on a regular basis and in this respect, effervescent tablets can be a lot easier than having to swallow a tablet. In addition to this, they can be a great way of ingesting medicine for individuals with sore throats or medical issues that make swallowing difficult and so are a viable alternative to regular tablets.

\section{Simple and Easy to Measure}

Effervescent tablets are easily dissolved into water or a liquid of your choice and then after a while are consistent, well mixed and ready to drink. Traditional tablets or powders, however, need to be measured and stirred in repeatedly to avoid an inconsistent drink with lumpy bits.

Even with stirring and measuring it is common to have an inconsistent drink with lumpy bits and an odd taste and this is where effervescent tablets are more efficient. Simply drop them in and they dissolve fully and evenly ensuring you get all the benefits of the tablet, as well as being able to comfortably drink it.

\section{To Sum Up}

Effervescent tablets are becoming increasingly popular and it is easy to see why. They provide a much more efficient way of taking supplements or medication due to being distributed evenly and much more quickly than regular tablets. In addition to this, they taste better as can be added to water or a liquid drink of your choice as well as being easier to take for people who may find it difficult to swallow.

All these factors combine to make effervescent tablets a very popular choice for those taking tablets for either dietary supplementation or medicinal reasons.

As per revised definition proposed to US FDA, Effervescent tablet is a tablet intended to be dissolved or dispersed in water before administration. Effervescent tablets are uncoated tablets that generally contain acid or acid salts (Citric, tartaric, Malic acid or any other suitable acid or acid anhydride) and carbonates or bicarbonates (Sodium, potassium or any other suitable alkali metal carbonate or hydrogen carbonate), which react rapidly in the presence 
of water by releasing carbon dioxide. Due to liberation in $\mathrm{CO}_{2}$ gas, the dissolution of API in water as well as taste masking effect is enhanced. ${ }^{16-20}$

The reaction between Citric acid and Sodium bicarbonate \& Tartaric acid and Sodium bicarbonate, which results in liberation of carbon dioxide shown as follows:
$\mathrm{C}_{6} \mathrm{H}_{8} \mathrm{O}_{7} \cdot \mathrm{H}_{2} \mathrm{O}+3 \mathrm{NaHCO}_{3}(\mathrm{aq}) \rightarrow \mathrm{Na}_{3} \mathrm{C}_{6} \mathrm{H}_{5} \mathrm{O}_{7}+4 \mathrm{H}_{2} \mathrm{O}+3 \mathrm{CO}_{2}(\mathrm{~g}) \uparrow$

Citric acid + Sodium bicarbonate $\rightarrow$ Sodium citrate + Water + Carbon dioxide

$\mathrm{C}_{4} \mathrm{H}_{6} \mathrm{O}_{6}+2 \mathrm{NaHCO}_{3} \rightarrow \mathrm{Na}_{2} \mathrm{C}_{4} \mathrm{H}_{4} \mathrm{O}_{6}+2 \mathrm{H}_{2} \mathrm{O}+2 \mathrm{CO}_{2}(\mathrm{~g}) \uparrow$

Tartaric acid + Sodium bicarbonate $\rightarrow$ Sodium tartrate + Water + Carbon dioxide

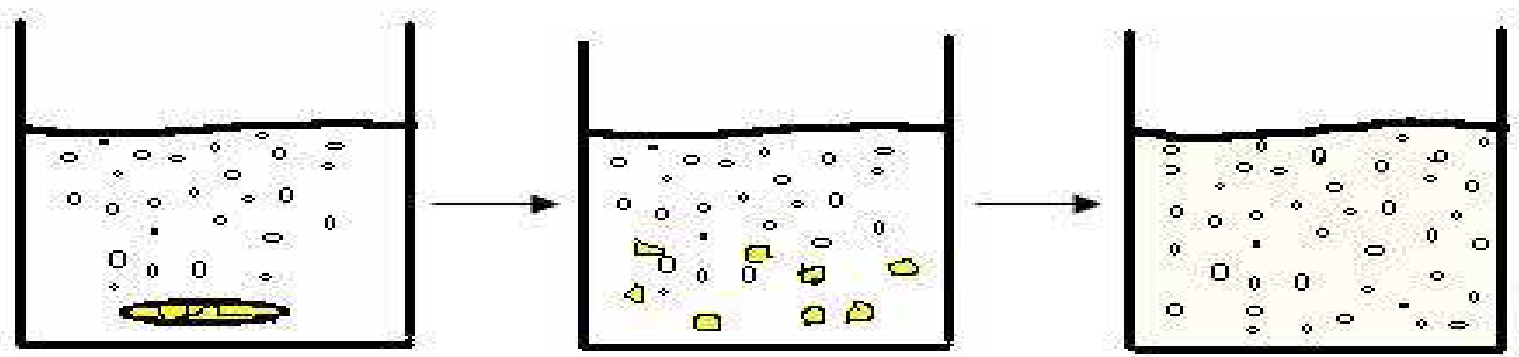

Figure 2: Mechanism of Effervescence

\section{FUNDAMENTALS OF EFFERVESCENTS: ${ }^{20-21}$}

Effervescence consists of a soluble organic acid and an alkali metal carbonate salt, one of which is often the API. Carbon dioxide is formed if this mixture comes into contact with water. Typical examples of the acids and alkalis used include:

$\begin{array}{ll}\text { - } & \text { Citric acid } \\ \text { - } & \text { Tartaric acid } \\ \text { - } & \text { Falic acid } \\ \text { - } & \text { Fumaric acid } \\ \text { - } & \text { Sodium bic acid } \\ \text { - } & \text { Sodium carbonate } \\ \text { - } & \text { Sodium sesquicarbonate } \\ \text { Potassium bicarbonate }\end{array}$

\section{ADVANTAGES OF EFFERVESCENT TABLETS: $22-23$}

- Fast onset of action.

- No need to swallow tablet.

- Good stomach and intestinal tolerance.

- More portability.

- Improved palatability.

- Superior stability.

- More consistent response.

- Incorporation of large amounts of active ingredients.

- Accurate Dosing.

- Improved Therapeutic Effect.

- In remote areas, especially where parenteral forms are not available due to prohibitive cost, lack of qualified medical staff, effervescent tablets could become an alternative.

\section{DISADVANTAGES OF EFFERVESCENT TABLETS: ${ }^{22-23}$}

- Unpleasant taste of some active ingredients.

- Larger tablets requiring special packaging materials.

- Relatively expensive to produce due to large amount of more or less expensive excipients and special production facilities.

- Clear solution is preferred for administration, although a fine dispersion is now universally acceptable.

\section{FORMULATION METHODOLOGIES: ${ }^{24-36}$}

\section{Wet Granulation:}

The most widely used process of agglomeration in pharmaceutical industry is wet granulation. Wet granulation process simply involves wet massing of the powder blend with a granulating liquid, wet sizing and drying. $24-36$

Important steps involved in the wet granulation

$\checkmark \quad$ Mixing of the drug(s) and excipients.

$\checkmark$ Preparation of binder solution.

$\checkmark$ Mixing of binder solution with powder mixture to form wet mass

$\checkmark \quad$ Drying of moist granules.

$\checkmark$ Mixing of screened granules with disintegrant, glidant, and lubricant.

\section{Advantages}

$\checkmark$ Permits mechanical handling of powders without loss of mix quality.

$\checkmark \quad$ Improves the flow of powders by increasing particle size and sphericity.

$\checkmark$ Increases and improves the uniformity of powder density.

\section{Limitation of wet granulation}

$\checkmark \quad$ The greatest disadvantage of wet granulation is its cost. It is an expensive process because of labor, time, equipment, energy and space requirements.

\section{$\checkmark \quad$ Loss of material during various stages of processing}

\section{Dry Granulation:}

In dry granulation process the powder mixture is compressed without the use of heat and solvent. It is the least desirable of all methods of granulation. The two basic procedures are to form a compact of material by compression and then to mill the compact to obtain a granules. Two methods are used for dry granulation. The more widely used method is slugging, where the powder is recompressed and the resulting tablet or slug are milled to yield the granules. The other method is to recompress the 
powder with pressure rolls using a machine such as Chilosonator. ${ }^{33-40}$

\section{Rollar Compaction:}

The compaction of powder by means of pressure roll can also be accomplished by a machine called chilsonator. Unlike tablet machine, the chilsonator turns out a compacted mass in a steady continuous flow. The powder is fed down between the rollers from the hopper which contains a spiral auger to feed the powder into the compaction zone. Like slugs, the aggregates are screened or milled for production into granules. ${ }^{40-43}$

Use: Use in the production of directly compressible excipients, the compaction of drugs and drug formulations, the granulation of inorganic materials, the granulation of dry herbal material and the production of immediate/sustained release formulations.

\section{Advancement in Granulations}

\section{Steam Granulation}

It is modification of wet granulation. Here steam is used as a binder instead of water. Its several benefits includes higher distribution uniformity, higher diffusion rate into powders, more favorable thermal balance] during drying step, steam granules are more spherical, have large surface area hence increased dissolution rate of the drug from granules, processing time is shorter therefore more number of tablets are produced per batch, compared to the use of organic solvent water vapour is environmentally friendly, no health hazards to operators, no restriction by ICH on traces left in the granules, freshly distilled steam is sterile and therefore the total count can be kept under control, lowers dissolution rate so can be used for preparation of taste masked granules without modifying availability of the drug. ${ }^{44-45}$

\section{Melt Granulation / Thermoplastic Granulation}

Here granulation is achieved by the addition of moldable binder. That is binder is in solid state at room temperature but melts in the temperature range of $50-80^{\circ} \mathrm{C}$. Melted binder then acts like a binding liquid. There is no need of drying phase since dried granules are obtained by cooling it to room temperature. $46-48$

\section{EVALUATION OF EFFERVESCENT TABLET}

\section{Pre-compression parameters:}

\section{Angle of repose $(\theta)$ :}

Angle of repose is defined as the maximum angle possible between the surface of a pile of the powder and horizontal plane. The frictional force in a loose powder or granules can be measured by angle of repose. It is an indicative of the flow properties of the powder. ${ }^{49-50}$

$$
\begin{aligned}
& \tan \boldsymbol{\theta}=\mathbf{H} / \mathbf{R} \\
& \boldsymbol{\theta}=\tan -\mathbf{1}(\mathbf{H} / \mathbf{R}) \\
& \text { Where, } \theta \text { is the angle of repose } \\
& \mathrm{H} \text { is height of pile } \\
& \mathrm{R} \text { is radius of the base of pile }
\end{aligned}
$$

The powder mixture was allowed to flow through the funnel fixed to a stand at definite height $(\mathrm{H})$. The angle of repose was then calculated by measuring the height \& radius of the heap of powder formed. Care was taken to see that the powder particles slip \& roll over each other through the sides of the funnel. Relationship between angle of repose and powder flow property.

Table 1: Angle of repose as an indication of powder flow properties

\begin{tabular}{|l|l|}
\hline Angle of repose (degrees) & Type of flow \\
\hline$<20$ & Excellent \\
\hline $20-30$ & Good \\
\hline $30-34$ & Passable \\
\hline$>40$ & Very poor \\
\hline
\end{tabular}

\section{Flow Rate:}

Flow rate of a powder has been defined as the rate at which the particular mass emerges through the office of funnel of a suitable diameter. The flow rate for granules of each formulation was determined by pouring accurately weighed quantities of granules in funnel with an orifice of $8 \mathrm{~mm}$ diameter. The time required for the complete granule mass to emerge out of the orifice was recorded using a stopwatch. The flow rate was calculated from following equation: 49

$$
\text { Flow Rate }=\frac{\text { Weight of granules }}{\text { Time in seconds }}
$$

\section{Bulk Density:}

The bulk density was obtained by dividing the mass of a powder by the bulk volume in $\mathrm{cm}^{3}$. The sample of about 50 $\mathrm{cm}^{3}$ of powder, previously been passed through a standard sieve no. 20, was carefully introduced into a $100 \mathrm{ml}$ graduated cylinder. The cylinder was dropped at 2 -second intervals onto a hard wood surface three times from a height of 1 inch. The bulk density of each formulation was then obtained by dividing the weight of sample in grams by the final volume in $\mathrm{cm}^{3}$ of the sample contained in the cylinder. It was calculated by using equation below: 49

$$
D_{\mathbf{f}}=\mathbf{M} / \mathbf{V}_{\mathbf{p}}
$$

Where

$$
\begin{aligned}
& D_{f}=\text { bulk density } \\
& M=\text { weight of samples in grams } \\
& V_{p}=\text { final volumes of granules in } \mathrm{cm}^{3}
\end{aligned}
$$

\section{Tapped density:}

The tapped density was obtained by dividing the mass of a powder by the tapped volume in $\mathrm{cm}^{3}$. The sample of about $50 \mathrm{~cm}^{3}$ of powder previously been passed through a standard sieve no. 20, is carefully introduced into a $100 \mathrm{ml}$ graduated cylinder. The cylinder was dropped at 2-second intervals onto a hard wood surface 100 times from a height of 1 inch. The tapped density of each formulation was then obtained by dividing the weight of sample in grams by the final tapped volume in $\mathrm{cm}^{3}$ of the sample contained in the cylinder. It was calculated by using equation given below:

$$
D_{0}=M / V_{p}
$$

Where

$$
\begin{aligned}
& D_{0}=\text { bulk density } \\
& M=\text { weight of samples in grams } \\
& V_{p}=\text { final volumes of granules in } \mathrm{cm}^{3}
\end{aligned}
$$

\section{Carr's Index:}

An indirect method of measuring powder flow from bulk densities was developed by Carr. The percentage 
compressibility of a powder was a direct measure of the potential powder arch or bridge strength and stability. Carr's index of each formulation was calculated according to equation given below:

$$
\% \text { compressibility }=\frac{\text { Df }- \text { Do }}{\text { Df }} \times 100
$$

Where,

$$
\begin{aligned}
& D_{f}=\text { Fluff or Poured bulk or bulk density. } \\
& D_{o}=\text { Tapped or Consolidated bulk density. }
\end{aligned}
$$

Table 2: Carr's Index as an indication of powder flow

\begin{tabular}{|l|l|}
\hline Carr's index (\%) & Type of flow \\
\hline $5-15$ & Excellent \\
\hline $12-16$ & Good \\
\hline $18-21$ & Fair to passable \\
\hline $23-35$ & Poor \\
\hline $33-38$ & Very poor \\
\hline$>40$ & Extremely poor \\
\hline
\end{tabular}

\section{Evaluation of Effervescent tablets}

Weight variation: Weight variation was determined to know whether different batches of tablets have uniformity. Weighed 20 tablets individually, calculated the average weight and compared the individual tablet weights to the average. The tablets meet the test if not more than two tablets are outside the \% limit and none of the tablet differ by more than two times the \% limit. Weight variation specification as per I.P. is shown in table no.6.18.

Table: 3: Weight variation specification.

\begin{tabular}{|l|l|l|}
\hline IP/BP & Limit & USP \\
\hline $80 \mathrm{mg}$ or less & $10 \%$ & $130 \mathrm{mg}$ or less \\
\hline $\begin{array}{l}\text { More than } 80 \mathrm{mg} \text { or } \\
\text { Less than } 250 \mathrm{mg}\end{array}$ & $7.5 \%$ & $130 \mathrm{mg}$ to $324 \mathrm{mg}$ \\
\hline $250 \mathrm{mg}$ or more & $5 \%$ & More than $324 \mathrm{mg}$ \\
\hline
\end{tabular}

\section{Tablet Thickness and Diameter:}

Thickness and diameter of tablets were important for uniformity of tablet size. Thickness and diameter were measured using Vernier Calipers.

\section{Tablet Hardness:}

The resistance of tablets to shipping or breakage under conditions of storage, transportation and handling before usage depends on its hardness. The hardness of tablet of each formulation was measured by Monsanto Hardness Tester. The hardness was measured in items of $\mathrm{kg} / \mathrm{cm}^{2}$. Hardness or tablet crushing strength is the force required to break a tablet in a diametric compression. The force is measured in $\mathrm{kg}$ and the hardness of about $3-5 \mathrm{~kg} / \mathrm{cm}^{2}$ is considered to be satisfactory for uncoated tablets.

\section{Friability (F):}

Friability of the tablet determined using Roche friabilator. This device subjects the tablet to the combined effect of abrasion and shock in a plastic chamber revolving at 25 rpm and dropping a tablet at a height of 6 inches in each revolution. Pre weighted sample of tablets was placed in the friabilator and were subjected to the 100 revolutions. Tablets were dusted using a soft muslin cloth and reweighed. USP limit is 0.5 to $1 \%$. The friability $(\mathrm{F})$ is given by the formula

$$
F=\frac{W \text { initial }-W \text { final }}{W \text { initial }} \times 100
$$

\section{Measurement of effervescence time}

A single tablet is placed in a beaker containing $200 \mathrm{ml}$ of purified water at $20^{\circ} \mathrm{C} \pm 1{ }^{\circ} \mathrm{C}$. Whenever a clear solution without particles is obtained effervescence time has finished.

The mean of three measurements of each formulation is to be reported.

\section{Determination of effervescent solution $\mathrm{pH}$}

$\mathrm{pH}$ of solution is determined with one tablet in $200 \mathrm{ml}$ of purified water at $20 \pm 1{ }^{\circ} \mathrm{C}$ by using $\mathrm{pH}$ meter, immediately after completing the dissolution time. Repeat experiment 3times for each formulation.

\section{Measurement of $\mathrm{CO}_{2}$ content}

One effervescent tablet solved in $100 \mathrm{ml}$ of $1 \mathrm{~N}$ sulphuric acid solution and weight changes were determined after dissolution end. The obtained weight difference is shown the amount (mg) of $\mathrm{CO}_{2}$ per tablet. Reports the averages of 3 determinations.

\section{Evaluation of the water content}

10 tablets of each formulation are dried in a desiccators containing of activated silica gel for 4 hours. Water content of $0.5 \%$ or less is acceptable.

\section{Uniformity of Content:}

10 tablets were selected randomly. Each tablet was transferred into a $50 \mathrm{~mL}$ volumetric flask, dissolved and diluted to $50 \mathrm{~mL}$ with phosphate buffer $\mathrm{pH}$ 6.8. One $\mathrm{ml}$ of this solution was diluted to $100 \mathrm{ml}$ with phosphate buffer $\mathrm{pH}$ 6.8. The amount of drug present in each tablet was determined by UV spectroscopy at $246 \mathrm{~nm}$. Standard limit for uniformity of content is

IP: - Active less than $10 \mathrm{mg}$ or $10 \%$,

BP:- Active less than $2 \mathrm{mg}$ or $2 \%$,

USP:- Active less than $25 \mathrm{mg}$ or $25 \%$.

$>10$ tabs limit NMT 1 tab deviate $85-115 \%$ \& none outside 75 - 125\% of the Avg value/IP/BP/USP (Relative Standard Deviation less than or equal to $6 \%)$,

$>\quad$ If 2 or 3 individual values are outside the limits 85 $115 \%$ of the Avg value, \& none outside $75-125 \%$ repeat for 20 tablets.

\section{Determination of the equilibrium moisture content}

Three desiccators are prepared containing saturated salt solutions of potassium nitrate (for creation $90 \% \mathrm{RH}$, at 18 ${ }^{\circ} \mathrm{C}$ ), sodium chloride (for creation $71 \% \mathrm{RH}$, at $18{ }^{\circ} \mathrm{C}$ ) and sodium nitrite (for creation $60 \% \mathrm{RH}$, at $18{ }^{\circ} \mathrm{C}$ ). Three tablets of each formulation are placed in desiccators. Then, the equilibrium moisture content is determined by Karl Fischer method and the autotitrator device in the first day and after 7 day.

\section{In-vitro disintegration time}

The process of breakdown of a tablet into smaller particles is called as disintegration. The in-vitro disintegration time of a tablet was determined using disintegration test apparatus as per I.P. specifications.

I.P. Specifications: Place one tablet in each of the 6 tubes of the basket. Add a disc to each tube and run the apparatus using phosphate buffer (pH-6.8) maintained at $37^{\circ} \pm 2^{\circ} \mathrm{C}$ as 
the immersion liquid. The assembly should be raised and lowered between 30 cycles per minute in the phosphate buffer (pH-6.8) maintained at $37^{\circ} \pm 2^{\circ} \mathrm{C}$. The time in seconds taken for complete disintegration of the tablet with no palpable mass remaining in the apparatus was measured and recorded. Standard limit for disintegration time is within $3 \mathrm{~min}$ in water at $25^{\circ} \mathrm{C} \pm 1^{\circ} \mathrm{C}$ (IP) and $15-25^{\circ} \mathrm{C}$ (BP). The results are given in table no.6.27.

\section{Dissolution Studies}

The release rate of Atorvastatin from mouth dissolving tablets was determined using USP Dissolution Testing Apparatus II (Paddle type). The dissolution medium used was $900 \mathrm{ml}$ of phosphate buffer $\mathrm{pH} 6.8$ which was maintained at $37 \pm 0.5^{\circ} \mathrm{C}$. The paddle speed was kept at 50 rpm throughout the study. Five $\mathrm{ml}$ of samples was withdrawn at every 5 minutes interval and diluted to $10 \mathrm{ml}$ then $5 \mathrm{ml}$ of fresh dissolution media maintained at the same temperature was replaniced. The samples were analysed spectrophotometrically at $246 \mathrm{~nm}$ using phosphate buffer pH 6.8 as blank. The raw dissolution data was analyzed for calculating the amount of drug released and percentage cumulative drug released at different time intervals.

\section{Release Kinetic Modeling: 22, 23, 25, 41, 49, 50}

In recent years, drug release from pharmaceutical dosage forms has been the subject of intense and profitable scientific developments. Whenever a new dosage form is developed form is developed, it is it is necessary to ensure that drug release occurs in an appropriate manner. The quantitative analysis of the values obtained in release tests is easier when mathematical formulas that express the release results as a function of some of the dosage forms characteristics are used. In some cases, these mathematic models are derived from the theoretical analysis of the occurring process. Drug dissolution from dosage forms has been described by kinetic models in which the dissolved amount of drug $(Q)$ is a function of the test time, $t$ or $Q=f$ $(t)$. Some analytical definitions of the $Q(t)$ function are commonly used, such as zero order, first order, Higuchi and Korsmeyer-Papas.

In-vitro dissolution has been recognized as an important pharmaceutical dosage form can influence the release element in drug development. Under certain conditions it kinetic be used as a surrogate for the assessment of bioequivalence. Several theories / kinetics models describe drug dissolution from immediate and modified release dosage forms. There are several models to represent the drug dissolution profiles where $f_{t}$ is a function of $t$ (time) related to the amount of drug dissolved from the pharmaceutical dosage system. In most cases, with tablets, capsules, coated forms or prolonged release forms that theoretical fundament does not exist and sometimes a more adequate empirical equations used. A water-soluble drug incorporated in a matrix is mainly released by diffusion, while for a low water-soluble drug the selferosion of the matrix will be the principal release mechanism. To accomplish these studies the cumulative profiles of the dissolved drug are $t$ more commonly used in opposition to their differential profiles. To compare dissolution profiles between two drug products model dependent (curve fitting), statistical analysis and model independent methods can be used.

\section{Zero order kinetics:}

Drug dissolution from dosage forms that do not disaggregate and release the drug slowly can be represented by the following equation

\section{$\mathbf{W}_{\mathbf{0}}-\mathrm{W}_{\mathrm{t}}=\mathbf{K t}$}

Where,

$\mathrm{W}_{\mathrm{o}}$ is the initial amount of drug in the dosage

form.

$\mathrm{W}_{\mathrm{t}}$ is the initial amount of drug in the dosage form at time $(\mathrm{t})$

$\mathrm{K}$ is the proportionality constant.

Dividing this equation by and simplify

\section{$\mathbf{F t}=$ Kot}

Where $\mathrm{ft}=1-\left(\mathrm{W}_{\mathrm{t}}-\mathrm{W}_{\mathrm{o}}\right)$ and $\mathrm{ft}$ represents the fraction of drug dissolved in time $t$ and $K_{o}$ the zero order of release constant.

This relation can be used to describe the modified release dosage form; the following relation can, in simple way to express this model

$$
Q_{t}=Q_{o}+K_{o} t
$$

Where,

$$
\begin{aligned}
& \mathrm{Q}_{\mathrm{t}} \text { is the amount of drug dissolved in time } \mathrm{t} \text {. } \\
& \mathrm{Q}_{\mathrm{o}} \text { is the amount of drug in the solution. }
\end{aligned}
$$

\section{First order kinetics:}

Gibaldi and Feldman first proposed the application of this model to drug dissolution studies in 1967 and later by Wagner in 1969. The dissolution phenomena of solid particles in a liquid media implies a surface action, as can be seen by the Noyes- Whitney equation.

\section{$\mathrm{DC} / \mathrm{dt}=\mathrm{K}(\mathrm{Cs}-\mathrm{C})$}

Where,

$\mathrm{C}$ is the concentration of the solute in time $\mathrm{t}$

Cs is the solubility in the equilibrium at expression temperature

\section{$\mathrm{K}$ is the first order proportionality}

\section{Higuchi model:}

Higuchi developed several theoretical models to study the release of water soluble and low soluble drops incorporated in the matrixes. The drug particles dispersed in a uniform matrix behaving as the diffusion media, the relation obtained was the following:

$$
f_{t}=Q=\sqrt{ } D\left(2 C-C_{s}\right) C_{s} t
$$

Where, unit area,

$\mathrm{Q}$ is the amount of drug released in time $t$, per

$\mathrm{C}$ is the drug initial concentration,

$\mathrm{C}_{\mathrm{s}}$ is the drug solubility in the matrix media.

$\mathrm{D}$ is the diffusivity of the drug molecules (diffusion constant in matrix).

$$
\text { dQ }=\mathbf{C d h}-1 / 2\left(C_{s} d h\right)
$$

but, in accordance to the first law $(\mathrm{dq} / \mathrm{dt}=\mathrm{DC} / \mathrm{h})$

Higuchi in 1962 proposed the following equation, for the case in which the drug is dissolution.

In general way it is possible to resume the Highuchi model to the following expression (generally known as the simplified Higuchi model). 


$$
F_{t}=K_{H} t^{1 / 2} \text {. }
$$

Where $\mathrm{K}_{\mathrm{H}}$ is the Highuchi dissolution constant treated sometimes in a different manner by different authors and theories. Higuchi describes drug release as a diffusion process based on Fick's law, square root time dependent.

\section{Korsmeyer - Peppas model:}

Korsmeyer et al., in 1983 was developed a simple, semi empirical model, relating exponentially the drug release to the elapsed time $(\mathrm{t})$.

$$
\mathbf{f}_{\mathbf{t}}=\mathbf{a t}
$$

a - is a constant incorporating structural and geometric characteristics of the drug dosage from, $n$ is the release exponent, indicate of the drug release mechanisms and the functions of $t$ is $\mathrm{M}_{\mathrm{t}} / \mathrm{M} \infty$ (Fractional release of drug). If drug release occurs under perfect sink condition, the following initial and boundary conditions, the following initial and boundary conditions can be assumed.

$$
\begin{aligned}
& t=0-d / 2<x<d / z \\
& t>0 . \quad x= \pm d / z
\end{aligned}
$$$$
\mathrm{C}=\mathrm{C}_{1}
$$

$\mathrm{C}_{0}$-is the initial drug concentration in the device.

$\mathrm{C}_{1}$-is the concentration of drug at the polymer water interface.

In the diffusion is the main drug release mechanism, a graphic representation the drug amount released, in the referred conditions, versus the square root of time should originate a straight line.

Table 4: Mathematical models used to describe drug release mechanism.

\begin{tabular}{|l|l|l|}
\hline S. No. & Mathematical model & Equation \\
\hline 1. & Zero order & $\mathrm{Qt}=\mathrm{Qo}+\mathrm{Kot}$ \\
\hline 2. & First order & $\ln \mathrm{Q}=\ln \mathrm{Qo}+\mathrm{K} 1 \mathrm{t}$ \\
\hline 3. & Higuchi & $\mathrm{Q} \mathrm{t}=\mathrm{KH} \sqrt{\mathrm{t}}$ \\
\hline 4. & Korsmeyer- Peppas & $\mathrm{Qt} / \mathrm{Q} \infty=\mathrm{Kktn}$ \\
\hline
\end{tabular}

\section{REFERENCES}

1. Gharti KP, Thapa P, Budhathoki U, Bhargava A, Formulation and in vitro evaluation of floating tablets of hydroxypropyl methylcellulose and polyethylene oxide using ranitidine hydrochloride as a model drug, Journal of Young Pharmacists, 2009; 4(4):201-208.

2. Singh BN, Kim KH, Floating drug delivery systems: an approach to oral controlled drug delivery via gastric retention, Journal of Controlled release, 2000; (63):235-59.

3. Deepali DW, Madhav MS, Jain DS, Gastroretentive Floating Microspheres: A Review, International Journal Of Pharmacy \&Technology, 2011; 3(4):1783-1799.

4. Singh LP, Rajesh KS, Umalkar DG, Chauhan VK, Rana VK, Vasava KS, Floating Effervescent Tablet: A Review, Journal of pharmaceutical and biomedical sciences, 2011; 5(11):1-6.

5. Agyilirah GA, Green M, DuCret R, Banker GS, Evaluation of the gastric retention properties of a cross-linked polymer coated tablet versus those of a non-disintegrating tablet, International Journal of Pharmaceutics, 1991; 75: 241-47.

6. Mohrle, R., Liberman, L,Schwartz L, Pharmaceutical Dosage Form, Vol. 1, Marcel Decker Inc., New York, 2005; 285- 292.

7. Lachman L, Liberman HA, Kanig JL. The theory and practice of industrial pharmacy. 3rd ed. Philadelphia: lea and febiger; 1986.

8. Swarbrick J, Boylan JC. Encyclopaedia of pharmaceutical technology. New York: Marcel Dekker; 2002

9. Harald S, Effervescent Dosage, Pharmaceutical Technology Europe, 2003; 15(4): 25-28.

10. Srinath KR, "Formulation and Evaluation of Effervescent tablets of Paracetamol", International Journal of Pharmaceutical Research \& Development, 2011; 3(3):76104.

11. Indian Pharmacopoeia, Government of India Ministry of Health and Family Welfare. Delhi: Controller of Publications 1996; 2: 35, 448, 554.

12. Howard CA, Lloyd A, Nocholas and Popovich, "Effervescent granules"8th edition "Pharmaceutical Dosage From and Drug Delivery" International Student Edition.-2000, 172-178.

13. Dixit N, Maurya SD, Sagar BPS, Sustained release drug delivery system, Indian Journal of Research in Pharmacy and Biotechnology, 2013; 1(3): 305-310.

14. Shimodaira S, Quality Verification of Dendritic Cell-Based Cancer Vaccine. Pharm Anal Acta, 2016; 7:467.

15. Hassali MA, Role of Pharmacists in Health Based NonGovernmental Organizations NGO: Prospects and Future Directions, Pharm Anal Acta. 2016; 7:467.

16. Vergeire DG, Usefulness of Cost Effectiveness: Evidence versus Applicability. Pharm Anal Acta, 2016; 7:456.

17. Wang C, Application of In Vitro Models in Developmental Neurotoxicity and Pharmaceutics Research, Journal of

Molecular Pharmaceutics \& Organic Process Research, 2015;3:122-128.

18. Lyubchenko YL, Nanoimaging for Molecular Pharmaceutics of Alzheimer's and other Neurodegenerative Disorders, Journal of Molecular Pharmaceutics \& Organic Process Research, 2013;1:107-111..

19. Skalkz BN, Note on the "Molecular Pharmaceutics and Organic Process". Journal of Molecular Pharmaceutics \& Organic Process Research, 2013; 1:104-110.

20. Foldvari $M$, Nanopharmaceutics Innovations in Gene Therapy: Moving Towards Non-Viral and Non-Invasive Delivery Methods. J Nanomedine Biotherapeutic Discovery. 2014; 4:135.

21. Maurya SD, Rawal RK, Jha S, Chauhan PS, Kumar A, Drug Loaded Beads: Current Status, American Journal of Pharm Tech Research, 2013; 3 (1): 331-337.

22. Sallam A, Bioequivalence of Two Oral Formulations of Modafinil Tablets in Healthy Male Subjects under Fed and Fasting Conditions. Journal of Bioequivalence Availability. 2015; 7:63-67.

23. Agatonovic KS, Biorelevant Dissolution Studies of Pioglitazone HCL Immediate Release Tablets and the Determination of an In Vitro In Vivo Correlation, Journal of Bioequivalence Availability, 2015; 7:086-089.

24. Abdul AS, Formulation, Evaluation and Mathematical Modeling of Clopidogrel Bisulphate \& Aspirin Immediate Release Bilayer Tablets, Pharmaceutca Anal Acta, 2012;3:194.

25. Biswas D and Halquist M, Using Biorelevant in Vitro Models Testing to Characterize Release of Non Oral Dosage Forms as another Tool for Safety. Journal of Pharmacovigilance, 2016; 4:153-160.

26. Bhattacharjee J. Mass Drugs Administration in India - A Failure Story. Epidemiology, Sunnyvale, 2016; 6:252.

27. Swain S and Beg S. Emergence in the Lipid-Based Nanostructured Systems for Optimizing Oral Delivery of Drugs. Pharmaceutical Regulatory Affairs, 2016; 5:157-163.

28. Kokardekar RR, Development and Evaluation of Sustained Release Microspheres of Glibenclamide by Emulsion Solvent Evaporation Method. Clinical Pharmacology and Biopharmaceutics, 2014; 3:127.

29. Cho SK. The Synergistic Effects of Pioglitazone on the Glucose-Lowering Action of Metformin in Relation to OCT1 and Gluts m-RNA Expression in Healthy Volunteer. Clinical Pharmacology and Biopharmaceutics, 2015; 3:129.

30. Ehrenpreis ED, A Survey of Lawsuits Filed for the Complaint of Tardive Dyskinesia Following Treatment with Metoclopramide. Clinical Pharmacology and Biopharmaceutics, 2015; 4:131. 
31. Patil JS, Hydrogel System: An Approach for Drug Delivery Modulation, Advance Pharmacoepidemiology and Drug Safety, 2015; 4:135.

32. Patil JS, Novel Tubercular Therapeutic Agents: Need of the Day, Advance Pharmacoepidemiology and Drug Safety, 2015; 4:137.

33. Obara T, Prevalence, Determinants, and Reasons for the NonReporting of Adverse Drug Reactions by Pharmacists in the Miyagi and Hokkaido Regions of Japan, Advance Pharmacoepidemiology and Drug Safety, 2015; 4:191.

34. Teoh BC, et al. Perceptions of Doctors and Pharmacists towards Medication Error Reporting and Prevention in Kedah, Malaysia: A Rasch Model Analysis. AdvPharmacoepidemiol Drug Saf. 2015; 4:192.

35. United States Pharmacopeia 31/National Formulary 26. Rockville MD USA: United States Pharmacopeial Convention; 2008.

36. Yanze FM, Duru C, Jacob M, A process to produce effervescent tablets: Fluidized bed dryer melt granulation. Drug Development \& Industrial Pharmacy, 2000; 26(11):1167-76.

37. Simona B, Tanja R, Using different experimental designs in drug excipient Compatibility Studies during the Preformulation development of a stable solid dosage formulation, Acta Chimica Slovenica, 2010; 57:895-903.

38. Larry LA and Stephan WH, Pharmaceutical Dosage Form: Tablets 3rd edition Vol. 1: 465.

39. Aboud HM, Elbary A, Ali AA, Enhanced dissolution of meloxicam from orodispersible tablets prepared by different methods, Bulletin of Faculty of Pharmacy, Cairo University, 2012;50:89-97.

40. Ahmed I, Aboul-Einien M, In vitro and in vivo evaluation of a fast disintegrating lyophilized dry emulsion tablet containing griseofulvin, European Journal of Pharmaceutical Sciences. 2007; 32:58-68.

41. Dhakar RC, Maurya SD, Dangi G, Kumar G , Gupta M, Kiroriwal S, Buccal Adhesive Dosage Forms As A NISDD: A Pharmaceutical Review, Research Pharmaceutica, 2010; 1(1): 46-59.
42. Aly AM, Amro BI, Hajji FD, Preparation and Evaluation of Rapidly Disintegrating Glimepiride Tablets. International Journal of Pharmaceutical Sciences and Nanotechnology, 2011; 3(4):1220-1229.

43. Ashish P, Harsoliya MS, Pathan JK, Shruti S, A ReviewFormulation of Mouth Dissolving tablet, International Journal of Pharmaceutical and Clinical Science, 2011; 1(1):18.

44. Sandhyarani G, Kumar KP, Formulation and evaluation of fast dissolving Tablet of imidapril, Indian Journal of Pharmaceutical Science\& Research, 2017;4(3):147-150.

45. Dhakar RC, Maurya SD, Gupta AK, Siddiqui AW Interpenetrating polymeric network hydrogel for stomachspecific drug delivery of clarithromycin: Preparation and evaluation, Asian Journal of Pharmaceutics, 2010; 4(4): 184189.

46. Dhakar RC, Maurya SD, Aggarawal S, Kumar G, Tilak VK, Design and evaluation of SRM microspheres of Metformin hydrochloride, Pharmacie Globale(IJCP), 2010; 1(07):1-6.

47. Dhakar RC, Maurya SD, Sagar BPS, Prajapati SK, Jain CP, Variables influencing the drug entrapment efficiency of microspheres: a pharmaceutical review, Der Pharmacia Lettre, 2010; 2(5): 102-116.

48. Sastry SV, Nyshdham JR, Fix JA, Recent technological advances in oral drug delivery: A review. Pharmaceutical Science and Technology Today, 2000; 1(3): 38-45.

49. Maurya SD, Tilak VK, Dhakar RC, Verma KK, Soni U, Gupta, Preparation and evaluation of floating tablet of famotidine through solid dispersion, International Journal of Current Research and Review, 2011; (2)1: 21-30.

50. Thoke SB, Sharma Y., Rawat S, Nangude, SFormulation development \& evaluation of effervescent tablet of Alendronate sodium with vitamin D3, Journal of Drug Delivery \& Therapeutics; 2013; 3(5):65-74.

51. Abolfazl A, Formulation, Characterization and Physicochemical Evaluation of Ranitidine Effervescent Tablets, Advanced Pharmaceutical Bulletin, 2013; 3(2): 315322. 